\title{
Aneurysm of the abdominal aorta with associated atheroma and bilateral renal atrophy: a case report
}

\author{
CAMPOS, D. ${ }^{1,2 *}$, GOULART, G. R. ${ }^{2}$, PACINI, G. S. ${ }^{1}$, THOMAZ, L. D. G. R. ${ }^{1}$, \\ BONATTO-COSTA, J. A. ${ }^{1,3}$, OLIVEIRA JUNIOR, L. P. ${ }^{1,3}$, MALYSZ, T. ${ }^{4}$ and \\ ROCHA, A. O. ${ }^{1}$
}

\author{
${ }^{1}$ Departamento de Ciências Básicas da Saúde, Universidade Federal de Ciências da Saúde de Porto Alegre - \\ UFCSPA, Avenida Sarmento Leite, 245, CEP 90050-170, Porto Alegre, RS, Brazil \\ ${ }^{2}$ Departamento de Biologia e Farmácia, Universidade de Santa Cruz do Sul - UNISC, Avenida Independência, \\ 2293, CEP 96815-900, Santa Cruz do Sul, RS, Brazil \\ ${ }^{3}$ Centro de Ciências da Saúde, Universidade do Vale do Rio do Sinos - UNISINOS, Avenida Unisinos, 950, \\ CEP 93000-000, São Leopoldo, RS, Brazil \\ ${ }^{4}$ Departamento de Ciências Morfológicas, Instituto de Ciências Básicas da Saúde, Universidade Federal do \\ Rio Grande do Sul - UFRGS, Avenida Sarmento Leite, 500, CEP 90050-170, Porto Alegre, RS, Brazil \\ *E-mail: dcampos@ufcspa.edu.br
}

\begin{abstract}
Introduction: An abdominal aortic aneurysm (AAA) (pathological enlargement of the aorta) can be developed in both men and women as they grow older. Patients present with atypical symptoms such as abdominal or flank pain, gastrointestinal hemorrhage, or shock. AAAs are among the main causes of death. The high morbidity and mortality associated with aneurysm rupture and repair represents a challenge for surgeons and high risk for patients. Therefore, AAA is a vascular condition that deserves constant attention, both for screening studies as therapeutic improvement. In screening studies, the prevalence of AAA in women is relatively rare (1\%). Materials and methods and results: During routine activities in the Laboratory of Human Anatomy from Federal University of Health Sciences of Porto Alegre, Brazil, it was observed a 87 years old female cadaver with AAA and with associated atheroma and bilateral renal atrophy. Conclusion: This study reported a case of AAA emphasizing some morphological, functional and clinical data about this vascular abnormality, in order to offer useful information to anatomists, radiologists, and surgeons.
\end{abstract}

Keywords: abdominal aortic, aneurysm, atheroma, cadaver, renal atrophy.

\section{Introduction}

Abdominal aortic aneurysm (AAA) (diameter greater than or equal to $3 \mathrm{~cm}$ ) has been recognized as an important health problem in the last decade. Statistics related to this disease caused great concern and its incidence is expected to increase in subsequent years, due to increased life expectancy of the population (JÓDAR, CARMONA, BURILLO et al., 2014).

Its importance is based on the high mortality rate that occurs with rupture, in contrast to the low mortality rate reported with elective surgical repair of specialized health services. It is estimated that the annual incidence of AAA rupture is eight cases per 100.000 inhabitants (BASNYAT, BIFFIN, MOSELEY et al., 1999) and is responsible for $2 \%$ of deaths in the population over 60 years (LAW, 1998).

Moreover, according to our knowledge the prevalence of AAA in the general population is not well known, and requires routine screening with high operating costs and difficult to measure.

Therefore, in this study we report an additional rare case of AAA with associated atheroma and bilateral renal atrophy (female cadaver), belonging to the didactical collection of the Laboratory of Human Anatomy from Federal University of Health Sciences of Porto Alegre, Brazil, emphasizing some aspects of this clinical and morphological vascular unusual configuration.

The cadaver was donated to the Laboratory of Human Anatomy from Federal University of Health Sciences of Porto Alegre, Brazil with a written consent before his death, that his body would be treated according to all ethical laws only for educational purposes, including any publications that would come up during dissection and would promote the medical science. The Research Ethics Committee of our institution approved this research project, under number 408/08-CEP.

\section{Case Report}

The case is based on the adult body caucasian female with the cause of death unknown, 87 years of age, belonging to the didactic collection of the Laboratory of Human Anatomy in the Federal University of Health Sciences of Porto Alegre, Brazil, it was observed that abdominal aorta showed typical proportions of aneurysm (Figure 1A-D). Furthermore, both kidneys, although located in normal positions, presenting atrophic dimensions (Figure 1D). The external measurements of the abdominal aorta were of $47.1 \mathrm{~mm}$ diameter and $96.1 \mathrm{~mm}$ in length. The internal measures $(1 \mathrm{~cm}$ under the origin of the 
superior mesenteric artery) of the abdominal aorta revealed a cross-sectional area of $1742.5 \mathrm{~mm}^{2}$, however the area that there is available for the blood flow is only $310.5 \mathrm{~mm}^{2}$. This reduction is created by an atherosclerotic plaque in the vessel wall (Figure 1B-C). The iliac arteries were also measured; the right iliac artery has a diameter of $13.8 \mathrm{~mm}$ while the left iliac artery has a diameter of $11.5 \mathrm{~mm}$.

The right kidney features $66.3 \mathrm{~mm}$ long, $48.4 \mathrm{~mm}$ wide and $17.1 \mathrm{~mm}$ thick. The left kidney features $86.3 \mathrm{~mm}$ long, $48.9 \mathrm{~mm}$ wide and $18.5 \mathrm{~mm}$ thick. The right and left renal arteries have diameters of 5.6 and $6.3 \mathrm{~mm}$, respectively (Figure 1D). All measurements were taken with the aid of a Image-Pro Plus Software [Image-Pro Plus 6.0; Media Cybernetics, Silver Spring, MD, USA].
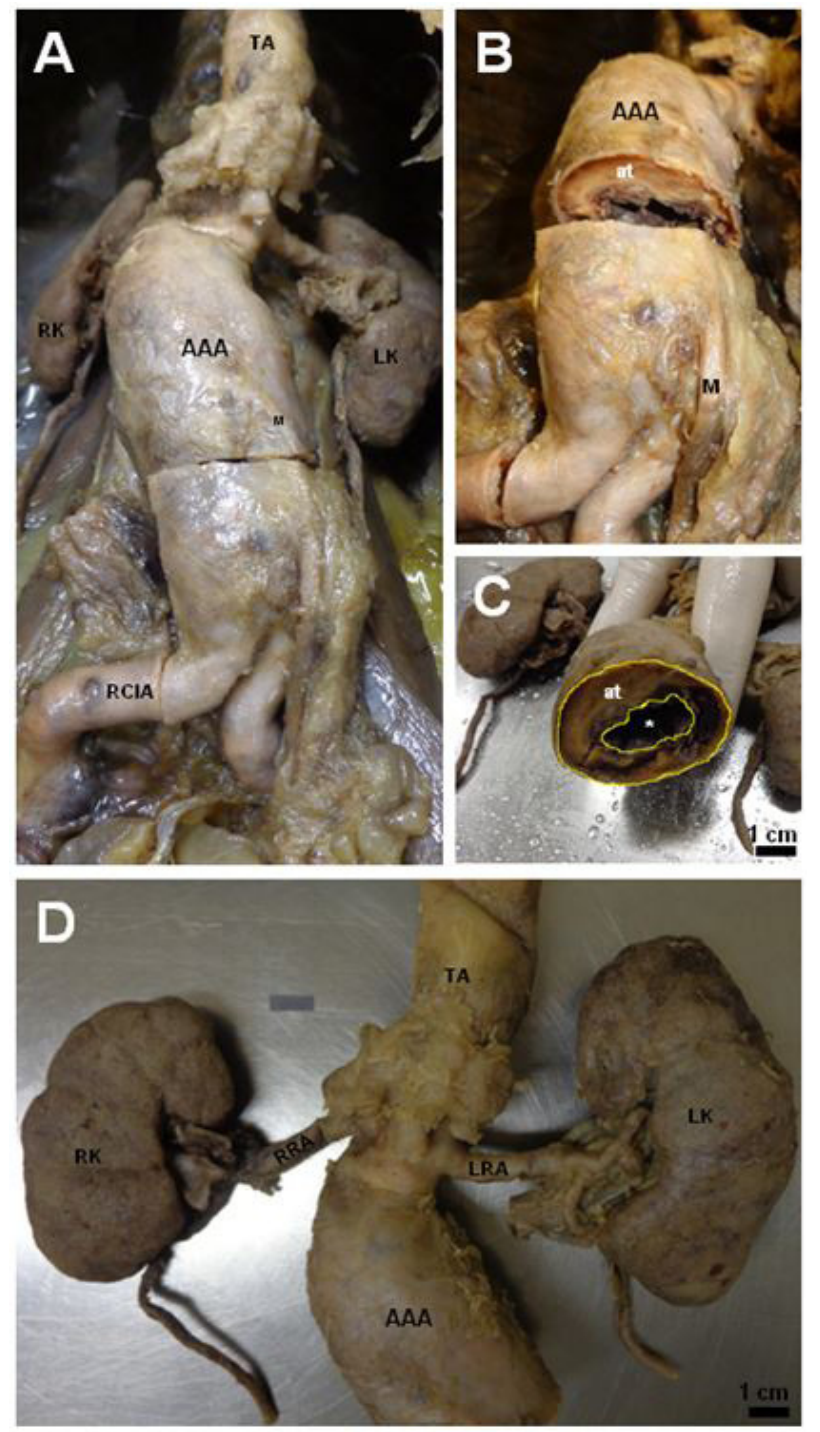

Figure 1. (A) Anterior view of the posterior wall of the abdomen showing abdominal aortic aneurysm (AAA); (B) Internal view of the abdominal aorta; (C) Transverse section of the abdominal aorta showing the atheroma (at) with a reduction of the available area $(*)$ for the blood flow; (D) Showing dissection photograph of significant reductions in overall size of the kidneys and associated vessels. (TA) thoracic aorta; $(\mathrm{M})$ inferior mesenteric artery; (RK) right kidney; (LK) left kidney; (RCIA) right common iliac artery; (RRA) right renal artery; (LRA) left renal artery.

\section{Discussion}

Although there are numerous studies describing different types of aneurysms in the thoracic or abdominal aorta, we did not find in the literature studies showing the internal dimensions of the different types of aneurysms. Data relating to the total cross-sectional area or the area available for blood flow are usually not described.

Therefore, we decided to present this data in our case report. Having the measurements obtained as guide, we see that a reduction of $82.2 \%$ of the total cross-sectional area of the central portion of the abdominal aorta. This effectively reduces the delivery of blood to the lower extremity of the body; furthermore, there is a consequent increase in cardiovascular overload. This is due to the stiffening of the vascular wall of the abdominal aorta caused by atheroma.

The vascular anomalies are usually asymptomatic (SALVE, 2012). However, patients with AAA present atypical symptoms such as abdominal or flank pain, gastrointestinal hemorrhage, or shock (DURDU, YILMAZ, SÖNMEZ et al., 2013). According to Zelaya, Goenezen, Dargon et al. (2014), if ruptured, AAAs carries a mortality rate of $90 \%$, claiming approximately 15.000 American lives annually. Generally, reparative surgery is performed if the AAA maximum transverse diameter measured on computed tomography scan or ultrasound imaging exceeds $5.5 \mathrm{~cm}$ or expands at a rate of $1 \mathrm{~cm} /$ year or more.

The AAA is an important disease in the practice of vascular surgeons, with a prevalence of $2 \%$ to $4 \%$ in the general population and the male: female relation of 5:1 (VANEK, 1988). It has been demonstrated that atherosclerosis is the main cause of these anomalies in adults. Other causes include connective tissue disorders, trauma, vasculitis, congenital, mycotic, and idiopathic (TUNCER, ONSEL TURK and ALIOGLU, 2013).

Atherosclerotic plaques are defined as complex in the presence of protruding atheroma with more than $4 \mathrm{~mm}$ in thickness, debris or movable ulcerated plaque, and defined as simple, if the plate is smaller than $4 \mathrm{~mm}$, commented without these characteristics (THENAPPAN, RAZA and MOVAHED, 2008).

Additionally, renal artery stenosis (RAS) is a common finding in patients with atherosclerosis. However, the situation of patients with RAS is complex. Multiple factors play a role in the pathogenesis of renal failure. Its prevalence is difficult to determine. Holley, Hunt, Brown et al. (1964) reported an incidence of $22.4 \%$ in a series of 295 autopsies. Atherosclerosis in other territories increases the prevalence of RAS, which can reach $20 \%$ in patients with coronary heart disease 56 or $33 \%$ to $50 \%$ in those with peripheral arterial disease (OLIN, MELIA, YOUNG et al., 1990).

Bilateral involvement has been reported in up to $44 \%$ of the patients with RAS (RIMMER and GENNARI, 1993). There is a relationship between the progression of RAS and the deterioration of renal function. However, poststenosis ischemia is just one of the factors identified in the pathogenesis of renal failure in the context of atherosclerotic renal artery disease, which involves hypertension, atherosclerosis of the renal parenchyma, hyperlipidemia and atheroembolism observed in cases of RAS (SURESH, LABOI, MAMTORA et al., 2000). The degree of stenosis and the severity of renal failure are not synonymous, since $10 \%$ of the metabolic activity of the kidney is provided for by the renal blood flow (EPSTEIN, 1997).

In addition, the abdominal aorta shown in our study did not have another aneurysm in its branches. However, although 
extremely rare, other branches of the aorta may also present aneurysms, such as the superior mesenteric artery, and the iliac arteries (RICCI, NAJARIAN and HEALEY, 2002).

Finally, we undertook this study with the aim of providing a more accurate report about a rare case of AAA, because of its interesting relationships with altered hemodynamics and predispose the patient to aneurysm formation. Moreover, this work aimed to provide a simple but multidisciplinary synthesis of the current knowledge concerning the morphogenesis, variation, and clinical significances of the AAA with associated atheroma and renal atrophy, and to help promoting future studies in this area.

Acknowledgements: The authors thank Marion Brilhante for her assistance with the capturing images.

\section{References}

BASNYAT, PS., BIFFIN, AH., MOSELEY, LG., HEDGES, AR. and LEWIS, MH. Mortality from ruptured abdominal aortic aneurysm in Wales. British Journal of Surgery, 1999, vol. 86, n. 6, p. 765-770. PMid:10383576. http://dx.doi.org/10.1046/j.13652168.1999.01170.x.

DURDU, T., YILMAZ, F., SÖNMEZ, BM., ÜLGEN, S., DEMIR, A., YILMAZ, MS., ARSLAN, ED. and HAKBILIR, O. An unusual presentation of ruptured abdominal aorta aneurysm. The American Journal of Case Reports, 2013, vol. 14, p. 267-269. PMid:23900449. http://dx.doi.org/10.12659/AJCR.889271.

EPSTEIN, FH. Oxygen and renal metabolism. Kidney International, 1997, vol. 51, n. 2, p. 381-385. PMid:9027710. http://dx.doi. org/10.1038/ki.1997.50.

HOLLEY, KE., HUNT, JC., BROWN, AL., KINCAID, OW. and SHEPS, SG. Renal artery stenosis: a clinical-pathologic study in normotensive and hypertensive patients. The American Journal of Medicine, 1964, vol. 37, n. 1, p. 14-22. PMid:14181143. http:// dx.doi.org/10.1016/0002-9343(64)90208-6.

JÓDAR, LS., CARMONA, PA., BURILLO, JMT. and TEJADA, RG. Prevalence of abdominal aortic aneurysm in a rural population of 65-80 year-old males. Semergen: Sociedad Espanola de Medicina Ruraly Generalista, 2014, vol. 40, n. 8, p. 425-430. PMid:25082506. http://dx.doi.org/10.1016/j.semerg.2014.01.013.
LAW, M. Screening for abdominal aortic aneurysms. British Medical Bulletin, 1998, vol. 54, n. 4, p. 903-913. PMid:10367422. http:// dx.doi.org/10.1093/oxfordjournals.bmb.a011737.

OLIN, JW., MELIA, M., YOUNG, JR., GRAOR, RA. and RISIUS, B. Prevalence of atherosclerotic renal artery stenosis in patients with atherosclerosis elsewhere. The American Journal of Medicine, 1990, vol. 88, n. IN, p. 46N-51N. PMid:2368764.

RICCI, MA., NAJARIAN, K. and HEALEY, CT. Successful endovascular treatment of a ruptured internal iliac aneurysm. Journal of Vascular Surgery, 2002, vol. 35, n. 6, p. 1274-1276. PMid:12042741. http:// dx.doi.org/10.1067/mva.2002.123329.

RIMMER, JM. and GENNARI, FJ. Atherosclerotic renovascular disease and progressive renal failure. Annals of Internal Medicine, 1993, vol. 118, n. 9, p. 712-719. PMid:8460859. http://dx.doi. org/10.7326/0003-4819-118-9-199305010-00010.

SALVE, VM. Coeliaco-mesenteric trunk: a rare case report. Journal of Morphological Science, 2012, vol. 29, p. 262-264.

SURESH, M., LABOI, P., MAMTORA, H. and KALRA, PA. Relationship of renal dysfunction to proximal arterial disease severity in atherosclerotic renovascular disease. Nephrology, Dialysis, Transplantation, 2000, vol. 15, n. 5, p. 631-636. PMid:10809803. http://dx.doi.org/10.1093/ndt/15.5.631.

THENAPPAN, T., RAZA, JA. and MOVAHED, A. Aortic atheromas: current concepts and controversier: a review of the literature. Echocardiography (Mount Kisco, N.Y.), 2008, vol. 25, n. 2, p. 198-207. PMid:18269565. http://dx.doi.org/10.1111/j.15408175.2007.00568.x.

TUNCER, E., ONSEL TURK, U. and ALIOGLU, E. Giant saccular aneurysm of the left main coronary artery. Journal of Geriatric Cardiology: JGC, 2013, vol. 10, n. 1, p. 110-112. PMid:23610581.

VANEK, VW. Combining abdominal aortic aneurysmectomy with gastrointestinal or biliary surgery. The American Surgeon, 1988, vol. 54, n. 5, p. 290-296. PMid:3364867.

ZELAYA, JE., GOENEZEN, S., DARGON, PT., AZARBAL, A-F. and RUGONYI, S. Improving the efficiency of abdominal aortic aneurysm wall stress computations. PLoS One, 2014, vol. 9, n. 7, p. e101353. PMid:25007052. http://dx.doi.org/10.1371/journal. pone. 0101353 .

Received January 31, 2016 Accepted February 14, 2017 